\title{
Parents' Perspectives on Having Their Children Interviewed for Research
}

\author{
Emily K. Hadley, ${ }^{1 *}$ Carrol A.M. Smith, ${ }^{2 * *}$ Agatha M. Gallo, ${ }^{3 \dagger}$ \\ Denise B. Angst, ${ }^{4 \ddagger}$ Kathleen A. Knafl $^{5 \uparrow}$
}

\author{
${ }^{1}$ University of Illinois at Chicago, Chicago, IL \\ ${ }^{2}$ School of Nursing, University of Michigan, Ann Arbor, MI \\ ${ }^{3}$ Department of Maternal Child Nursing, College of Nursing, University of \\ Illinois at Chicago, M/C 802, 845 S. Damen Ave., Chicago, IL 60612 \\ ${ }^{4}$ Advocate Center for Pediatric Research, Advocate Health Care, Park Ridge, IL \\ ${ }^{5}$ School of Nursing, Oregon Health \& Science University, Portland, OR \\ Accepted 4 July 2007
}

\begin{abstract}
We describe parents' perspectives on research interviews with their children with single gene conditions. One hundred forty-two parents were interviewed between 2002 and 2003 in a larger study using a qualitative descriptive design. Two questions from the semi-structured interview guide were used to identify parents' perspectives about future interviews. Almost all of the parents said they would allow an interview with their children, but some parents specified stipulations. These stipulations included: focusing on age-appropriate information, limiting information with child, considering input from parents, and providing a child-oriented environment. Knowing this information, researchers can prepare to work more collaboratively with parents and include them more fully in the research process. (๑) 2007 Wiley Periodicals, Inc. Res Nurs Health 31:4-11, 2008
\end{abstract}

Keywords: interviewing children; genetic condition; qualitative research

Because children's viewpoints are often different from those of their parents, obtaining viewpoints directly from children is essential. Researchers have addressed interviewing children, focusing on developmentally appropriate strategies (Garbarino, Stott, \& Faculty of Erikson Institute, 1992; Instone,
2002; Morison, Moir, \& Kwansa, 2000), qualitative methodologies (Docherty \& Sandelowski, 1999; Faux, Walsh, \& Deatrick, 1988; Kortesluoma, Hentinen, \& Nikkonen, 2003), and cultural sensitivity (Dennis \& Giangreco, 1996). Yet, the perspectives of the parents who must give permission for

The authors acknowledge Dr. Suzanne Feetham for her ongoing consultation on this research and critical review of the article. A special thanks to all the parents who participated in this study.

Contract grant sponsor: National Human Genome Research Institute (NHGRI); Ethical Legal and Social Implications (ELSI) Research Program; Contract grant number: R01 HG002036.

Correspondence to Agatha M. Gallo.

*Proiect Director.

**Postdoctoral Research Fellow.

†Professor.

${ }^{\ddagger}$ Director.

"Elisabeth N. Gray Distinguished Professor and Senior Associate Dean for Research and Faculty Affairs.

Published online 28 December 2007 in Wiley InterScience

(www.interscience.wiley.com). DOI: 10.1002/nur.20231 
their minor children to be interviewed rarely have been studied. Therefore, the purpose of our study was to describe the perspectives of parents of children with genetic conditions on having their children interviewed.

\section{REVIEW OF LITERATURE}

\section{Federal Initiatives}

Federal agencies (National Institutes of Health, 1998) and federal law (Pediatric Research Equity Act, 2003) have mandated that children be included in clinical research. Including children and adolescents (hereafter referred to as children) in research is advocated by many organizations both to inform interventions and to guide public policy (American Academy of Pediatrics Committee on Bioethics, 1995; Santelli et al., 2003; U.S. Congress, Office of Technology Assessment, 1991). In every study that includes children, certain safeguards must be in place to protect them (Code of Federal Regulations, 2005), including assessment of risks and potential benefits, parental permission, and child assent. Additional policies and procedures have been established by the National Institutes of Health and the Federal Drug Administration for children participating in clinical research (Field \& Behrman, 2004).

\section{Ethics of Research With Children}

Researchers are guided by the ethical principles governing research detailed in The Belmont Report (National Commission for the Protection of Human Subjects of Biomedical and Behavioral Research, 1978). These principles include respect for persons, beneficence, and justice. Hall, Stevens, and Pletsch (2001) described these principles in relation to children's research participation. The principle of respect is met by having parents give permission for their child's participation in research and obtaining child assent when appropriate. The researchers noted, however, that controversy exists here, as adolescents may be able to provide their own informed consent without involving their parents. The principle of beneficence requires special considerations of benefits and risks of participation to ensure minimal risk of harm or discomfort to participants and to secure their well-being. This would relate to concerns parents may feel about the emotional discomfort their child could experience from participation in research. The third principle, justice, ensures that vulnerable populations' needs are addressed, and comparable people are treated equally. By including children, the principle of justice is met. Rodriguez, Tuvemo, and Hansson (2006) found in their research that most parents believed there was a need to conduct more research that directly involved children.

\section{Permission for Children's Participation in Research}

Current laws require parental permission for children under the age of 18 to assent to participate in research. Researchers have reported on parents' decisionmaking regarding their children's participation in clinical trials (Snethen, Broome, Knafl, Deatrick, \& Angst, 2006) and on decisions and experiences related to providing informed consent and assent for a child's participation in research (Pletsch \& Stevens, 2001; Ungar, Joffe, \& Kodish, 2006). By conducting interviews with children about their genetic conditions, it is possible to collect data that are otherwise unobtainable and have been inadequately captured to date (Kortesluoma et al., 2003). However, in order to interview children, parents' perspectives on interviewing their children must be understood. Parents may be unwilling to provide permission unless they feel their own views are considered. As Smyth (2001, p. 1378) observed: "We need to develop and strengthen research with children by enlisting the active collaboration of parents and children themselves."

\section{METHODS}

This analysis was based on data from a larger mixed methods study of 86 families (142 parents/caregivers) who were interviewed about how they accessed, interpreted, and conveyed information related to their child's genetic condition (Gallo, Knafl, \& Angst, 2001). All respondents were either parents or caregivers of a child with a single gene condition. The term parents is used throughout this article to refer to both parents and primary caregivers.

We used a qualitative descriptive design (Sandelowski, 2000), including maximum variation purposeful sampling, semi-structured interviews, and qualitative content analysis. Such studies yield comprehensive low-inference interpretive summaries of data.

\section{Sample}

The sample of 142 parents was recruited from three outpatient specialty clinical sites in the greater 
Chicago metropolitan area. We selected the genetic conditions because of their known genetic inheritance patterns, varying modes of transmission, clinical features, incidence in varied ethnic groups, association with normal/near normal cognitive functioning, and expected survival into adulthood. Participants were selected to achieve maximum variation, document diversity, and understand variation (Patton, 2002). Eligible families included those whose parents spoke English and whose children with the genetic condition were: school age (preschool through high school), biological for at least one parent, and within 2 years of the appropriate grade in school. In two-parent families, both parents were invited to participate.

\section{Sample Characteristics}

Almost all $(n=133,94 \%)$ of the participants were biological parents of the child with the genetic condition. The remaining nine participants consisted of two stepmothers, two stepfathers, two aunts, two grandmothers, and an adult sibling of the child. Parents had a child with a diagnosis of sickle cell disease $(n=29,33.7 \%)$, phenylketonuria $(n=$ $16,18.6 \%)$, cystic fibrosis $(n=16,18.6 \%)$, neurofibromatosis $(n=10,11.6 \%)$, hemophilia $(n=6$, $7.0 \%)$, thalassemia $(n=4,4.7 \%)$, von Willebrand disease $(n=1,1.2 \%)$, or Marfan syndrome $(n=4$, $4.7 \%)$. The participants ranged in age from 18 to 57 years $(M=39.84, S D=7.59$ years $)$. Most were either White $(n=83,59 \%)$ or Black $(n=41,29 \%)$, and Catholic $(n=52,37 \%)$ or Protestant $(n=48$, $34 \%)$. Sixty-three percent $(n=89)$ of the sample was female and the majority $(n=109,77 \%)$ was married. Thirty-seven percent $(n=53)$ completed college or graduate school; $34 \%(n=48)$ completed some college. Only $5 \%(n=7)$ of the participants had not completed high school. Most were employed full-time $(n=80,56 \%) ; 27 \%$ $(n=38)$ of the sample was not employed. Of the 135 parents who provided annual household income, $23 \%(n=33)$ reported household incomes $<\$ 30,000$ per year, and $37 \%(n=52)$ reported incomes $\geq \$ 75,000$. The children ranged in age from 3.7 to 15.9 years $(M=10.1, S D=3.18$ years $)$, and about half $(n=45,52 \%)$ were female.

\section{Data Collection Procedures}

Prior to data collection, institutional review board approval was obtained from all sites. Parents were contacted about participating either by letter from the clinic director or in person by a member of the research team during a clinic visit. The interviews were conducted by a member of the project team, all of whom were advanced practice nurses. Interviews were held in a location chosen by the parents (usually the family's home or a private room at the university or clinical agency). Each parent was interviewed individually; interviews typically lasted 60 to 120 minutes. At the conclusion of data collection, each parent received $\$ 50$ for his/her time and travel.

Parents were asked to respond to the following two questions with limited probing by interviewers: (a) "Under what circumstances, if any, would you give permission for an interview with your child? (b) If you agreed to have us interview your child, what questions or topics would you be uncomfortable with and not want us to ask your child, such as questions regarding how the condition is passed on in the family or how information is shared within the family and with others? What questions or topics would you be comfortable with?"

\section{Data Analysis}

Parent interviews were digitally recorded and transcribed verbatim; they were then compared to the audio-recorded interviews to ensure accuracy. Transcripts were coded using ATLAS.ti software (version 4.2). For this analysis, parent responses for two of the codes ("permission" and "comfort") were examined. Following guidelines for data management in Miles and Huberman (1994), one team member constructed a matrix of parents' comments that facilitated comparisons of parents' willingness to give permission for their children to participate in an interview and stipulations they placed on the interview. Another matrix was constructed by categorizing similar verbatim comments from parents' remarks on interview stipulations; this process resulted in the identification of four broad themes. Two additional team members collaborated to verify the labels and definitions of the themes based on the parents' comments.

\section{RESULTS}

\section{Giving Permission for an Interview}

Almost all $(n=139,98 \%)$ parents stated they would be willing to give permission for a future research interview with their children, and they articulated the important benefits from the 
interviews. Three parents were uncertain about their decision to allow their child to participate in a future interview. In all three of these families, the second parents said they would give permission for a future interview. Several parents emphasized the importance of including children in research. As one mother of a 9-year-old child with sickle cell disease said:

I think they need to interview children, starting from [age] 9 on up to see what [their] point of view is. They can tell you more about [their] pain than a parent can. It'd be good if they would get a study to ask these kids [themselves] so they'll learn from a child's point of view ...Kids can tell you things that a parent can't.

Another mother of an 8-year-old child with cystic fibrosis stated:

Actually, I would think it [interviewing children] would be a really good thing. . It may help the parents find out and understand what they know about how they are dealing with it.

\section{Parent Stipulations}

While 42 of the 139 parents (30\%) had no stipulations for interviewing their child, 97 (70\%) specified stipulations. Overall, parents gave one $(n=53,38 \%)$, two $(n=27,19 \%)$, three $(n=15,11 \%)$, or four $(n=2,1 \%)$ stipulations, suggesting a range of concerns that encompassed all genetic conditions and represented varying ages of children.

Focusing on age-appropriate information. Parents were concerned about how their children at different developmental stages would be affected by participating in the interviews. Twenty-four (25\%) parents who specified stipulations said they would give permission for their children to participate in an interview as long as the questions focused on developmentally appropriate information. Three parents specifically stated their children would have to be older (i.e., early to midadolescence) before they would give permission for them to participate in an interview. Similarly, 11 parents $(11 \%)$ wanted their children to be knowledgeable about the genetic condition and to have been "talked to" by parents or health providers about the condition prior to being interviewed. One father stated his 3-year-old daughter with phenylketonuria could participate in an interview "when she is old enough to understand and articulate in a reasonable manner her condition."
Limiting questions asked of the child. Parents wished to protect their children from some of the realities of their genetic conditions by limiting questions asked of their children in an interview. Thirty-five parents (36\%) who specified stipulations stated they would give permission for their child to be interviewed if they were assured that particular topics would not be discussed. The most frequently mentioned topics were related to life expectancy or the possible fatal nature of the condition $(n=13)$ and reproductive or genetic implications of the condition $(n=13)$. All of the parents who were concerned about life expectancy had a child with either sickle cell disease or cystic fibrosis, conditions with the potential for a shortened lifespan. For example, a father of a 15year-old daughter with sickle cell disease stated that he did not want interviewers to discuss "anything that has to do with the disease being fatal because I don't want her thinking about anything like that right now. I want her to live her life for today, not tomorrow." Those parents who did not want reproductive implications or genetic aspects of the condition discussed with the child represented a variety of diagnoses: cystic fibrosis $(n=4)$, phenylketonuria $(n=3)$, neurofibromatosis $(n=4)$, hemophilia $(n=1)$, and thalassemia $(n=1)$. One mother said she did not want her child with cystic fibrosis to be asked questions about the likelihood of the child being infertile saying, "I think it [infertility] is a sensitive topic for a 13-yearold." Four parents did not want their children involved in discussions on genetic aspects of the condition until the children were "older" or until the children were aware of the genetic implications.

Nine parents (9\%) were concerned about interview questions that were of a personal nature. Three of these parents mentioned that they would prefer interview questions be focused on the genetic condition and not on personal information about family and friends. Two single mothers indicated they did not want questions focused on the child's biological father. Two parents commented they did not want the financial impact of the condition on the family discussed with the child. A mother of a 9-year-old child with thalassemia said, "I do not want her to be burdened... that we are spending so much or that she would be an expense [to] the family. I do not want her to know." Another mother whose spouse (the child's father) also had Marfan syndrome did not want questions about the father's condition discussed as the child is "sensitive" to these type of questions. One father whose daughter has thalassemia indicated the child might 
be uncomfortable discussing how information is shared outside the family because she "wants to keep this for herself" and did not know how other children would react to the child's diagnosis.

Considering input from parents. Parents wanted to be part of the interviewing process when they gave permission for their children to be interviewed. Some parents would agree to have their children participate in interviews as long as the parents were able to review the interview questions beforehand $(n=19,20 \%)$ or were present for the interview $(n=17,18 \%)$. As one father of a 13-year-old with neurofibromatosis commented:

I would think that I would like either [child's mom] or I to be present during the interview, but I wouldn't want that to bias [child] either. So, I'd have to really think about that and tread on that one very cautiously. The reason that I would want to be there is to hear the communication and make sure that I felt that that was a question that really should be asked of [child] at her age.

Six other parents indicated they might want to be present during the interview. One additional parent wanted to have someone familiar present for the interview, but indicated that this individual did not have to be a parent. One father specified that he would like to be in the same geographic location as the child, but not necessarily present during the interview itself. A mother wanted to be aware of the outcome of the interview, saying she would like "to know what he is thinking." These parents had children with ages ranging from 4 to 14 years and diagnoses of sickle cell disease, phenylketonuria, cystic fibrosis, neurofibromatosis, or Marfan syndrome.

Providing a child-oriented environment. Eighteen (19\%) of the parents said they would agree to have their children interviewed only if the children were willing to participate in the interview. Nine of these parents specifically indicated they would leave the decision concerning participation up to their children. A mother of a 9-yearold daughter with thalassemia said, "I would talk to Jane and, if she agrees, only then. This is her decision completely."

Parents $(n=8,8 \%)$ said they would give permission for an interview with their children as long as a comfortable and safe interview environment was provided. For example, three parents stated the interview should be conducted in a relaxed, unstructured setting such as the child's home. Three parents had specific sugges- tions about the length of the interview, the child's health at the time of the interview, and the use of photography. One parent whose child has hemophilia stated that the interview should be limited to 1 hour while another parent with a daughter with sickle cell disease remarked that the child should not be interviewed when "sick." A one-on-one interview with no photographs was cited as the stipulation by another parent of a child with Marfan syndrome. Two parents expressed concerns related to the qualifications of the interviewer. While one father said he would like information about the interviewer, a mother said she would agree to have the child interviewed on the condition that the child was interviewed by someone trustworthy, that is, "If I feel that she's with somebody that's trustworthy, I don't think it would be a problem."

\section{DISCUSSION}

In light of recent initiatives to increase the participation of children in research, it is important to learn the perspectives, and gain the trust, of the parents who must give permission. The parents who were willing to give permission for their children to participate in a future research interview often placed stipulations on conducting the interviews. These stipulations have implications for how parents could be appropriately involved in preparations for their child to be interviewed. Because some parents thought the child's development was key when considering whether their children could be interviewed, they wanted the interview questions to be developmentally and age-appropriate. Researchers could structure an advisory board of parents as consultants in the preparation of the interview guide. Through focus groups, parents could be solicited for their ideas about interview questions for both a younger and an older age group.

Parents may be asked for input regarding interview topics or their preferred way to phrase questions. By involving them in the development of the interview guide, parents' concerns about life expectancy, genetics, and reproductive issues can be addressed. Asking for parental input supports our previous findings indicating many parents (49\%) openly shared information with their children about the genetic condition, but some $(41 \%)$ selectively shared sensitive information, such as life expectancy or reproduction (Gallo, Angst, Knafl, Hadley, \& Smith, 2005). Encouraging parents to review the interview questions and to negotiate the setting for the interview could 
provide them the opportunity to participate actively in their children's interview process and would enhance recruitment and retention of child participants.

Most parents of children with chronic conditions want to normalize their children's lives by supporting child and family routines (Bossert, Holaday, Harkins, \& Turner-Henson, 1990; Deatrick, Knafl, \& Murphy-Moore, 1999; Fisher, 2001; Knafl \& Deatrick, 2002; Robinson, 1993). Some families who normalize, however, decide to limit communication with their children about the condition. By talking to parents in advance about their concerns, major breaches in conversations with children can be avoided that parents might consider upsetting or frightening to their children. There may be other developmental issues or concerns particular to a family that could be addressed if researchers gave parents the time and attention to express themselves.

Although some children may feel more comfortable with a parent present during the child interview, parental presence would probably influence what the child would tell the interviewer. In cases where parents requested to be with the child, interviewers could talk with parents about their reasons for wanting to be present and the benefits of separate child interviews to encourage open communication and to capture children's views about their condition (Eder \& Fingerson, 2002; Kortesluoma et al., 2003). For parents who want to review interview questions, interviewers can offer them this opportunity before they give permission for their children to participate in an interview. Through this process, interviewers must remember that giving permission is a parent's personal choice; parents deserve respect and support in their decisions.

A benefit of our study is the insight it provides into parents' ideas about interviewing their children with a genetic condition. Because of the variety of genetic conditions included in this study and the wide age range of the children, an excellent cross-section of parents' comments was obtained. Parents' comments helped us to see what was important to them in fulfilling their roles as the legal gatekeepers of their children's participation in research. As Dixon-Woods, Young, and Heney (2002, p. 173) suggested, "the unique moral and legal status of parents as guardians of their children's well-being and the complexity of their roles as caregivers, advocates, and individuals..." cannot be overlooked when preparing to include children in research protocols.

Our study is limited in that it focused on parents' responses to two specific interview questions that were part of a more extensive interview guide used in a larger mixed methods study on parents accessing, interpreting, and conveying information to others. Although parents were asked to expand on their perspectives, any probing around this topic was limited. In addition, these two questions were asked at the end of the interview, and respondent fatigue may have affected the depth of parents' responses. As the parents had already agreed to participate in our study, they may have had a favorable view of research participation and be more willing to have their children participate in research than parents who were not included in our sample. Furthermore, these parents may have been more inclined to have their children interviewed because we had already established rapport and trust with the parents. Parents were asked solely about their children's participation in research interviews, and the findings do not reflect parents' views about their children's participation in other types of research, such as clinical trials, where other issues may prevail.

\section{IMPLICATIONS FOR FUTURE RESEARCH}

Interviewing children for research purposes is an important endeavor. Although children have been interviewed in studies of chronic illness (Angst, 1992; Gallo \& Szychlinski, 2003; Knafl, Breitmayer, Gallo, \& Zoeller, 1996), there is little reported about their perceptions and knowledge of their own genetic conditions. Interviewing children affirms the importance of their perspectives and their role in the management of their conditions and an interest in them as individuals, and it models a preferred style of interaction for parents and guardians (Instone, 2002).

Future research could extend this analysis to younger and older children, children without genetic conditions, and siblings who are unaffected by, or carriers of, the genetic condition. The use of more structured interview questions or development of a standardized questionnaire would probe for detailed information on parents' concerns about their children's participation in a study. Following children's interviews, parents could be asked if concerns about their children's participation were addressed. Considering parents' perspectives provides researchers with essential information to address the specific concerns of parents when they are asked permission for their children to participate in research. 


\section{REFERENCES}

American Academy of Pediatrics Committee on Bioethics. (1995). Informed consent, parental permission, and assent in pediatric practice. Pediatrics, 95, 314-317.

Angst, D. (1992). Defining and managing cystic fibrosis: The experience of school age children and families. Publication Number AAT 9224755, Dissertation Abstracts International-B 53/04, p. 1779, October, 1992. Abstract retrieved June 8, 2006, from http:// wwwlib.umi.com/dissertations/fullcit/9224755

Bossert, E., Holaday, B., Harkins, A., \& Turner-Henson, A. (1990). Strategies of normalization used by parents of chronically ill school age children. Journal of Child \& Adolescent Psychiatric \& Mental Health Nursing, 3, 57-61.

Code of Federal Regulations. (2005, June 23). Title 45, Public Welfare, Department of Health and Human Services, Part 46, Federal Policy for the Protection of Research Subjects, Subpart D, Additional Protection for Children Involved as Subjects in Research. 48 Federal Register 9818. Retrieved November 20, 2006, from http://www.hhs.gov/ohrp/humansubjects/ guidance/45cfr46.htmsubpartd

Deatrick, J.A., Knafl, K.A., \& Murphy-Moore, C. (1999). Clarifying the concept of normalization. Image: Journal of Nursing Scholarship, 31, 209-214.

Dennis, R.E., \& Giangreco, M.F. (1996). Creating conversation: Reflections on cultural sensitivity in family interviewing. Exceptional Children, 63, 103116.

Dixon-Woods, M., Young, B., \& Heney, D. (2002). Childhood cancer and users' views: A critical perspective. European Journal of Cancer Care, 11, $173-177$.

Docherty, S., \& Sandelowski, M. (1999). Interviewing children. Research in Nursing \& Health, 22, 177185.

Eder, D., \& Fingerson, L. (2002). Interviewing children and adolescents. In J.A. Gubrium \& J.F. Holstein (Eds.), Handbook of interview research: Context and method (pp. 181-202). Thousand Oaks, CA: Sage.

Faux, S.A., Walsh, M., \& Deatrick, J.A. (1988). Intensive interviewing with children and adolescents. Western Journal of Nursing Research, 10, 180-194.

Field, M.J., Behrman, R.E. (Eds.). (2004). Ethical conduct of clinical research involving children. Committee on Clinical Research Involving Children, Board on Health Sciences Policy, Institute of Medicine of the National Academies. Washington, DC: The National Academies Press.

Fisher, H.R. (2001). The needs of parents with chronically sick children: A literature review. Journal of Advanced Nursing, 36, 600-607.

Gallo, A.M., Angst, D., Knafl, K.A., Hadley, E., \& Smith, C. (2005). Parents sharing information with their children about genetic conditions. Journal of Pediatric Health Care, 19, 267-275.

Gallo, A., Knafl, K., \& Angst, D. (2001). Parent's interpretation and use of genetic information. Funded by the National Institutes of Health, National Human Genome Research Institute, Ethical, Legal \& Social Implications Program. Abstract retrieved May 10, 2005, from http://crisp.cit.nih.gov/crisp/CRISP_LIB.getdoc? textkey $=6383482 \&$ p_grant_num $=1$ R01HG00203601A2\&p_query=\&ticket $=39522903 \&$ p_audit_ session_id=246091132\&p_keywords $=$

Gallo, A.M., \& Szychlinski, C. (2003). Self-perception and family functioning in healthy school-age siblings of children with asthma and diabetes and healthy children. Journal of Family Nursing, 9, 414434.

Garbarino, J., Stott, F., \& Faculty of Erikson Institute. (1992). What children can tell us: Eliciting, interpreting, and evaluating information from children. San Francisco: Jossey-Bass.

Hall, J.M., Stevens, P.E., \& Pletsch, P.K. (2001). Team research using qualitative methods: Investigating children's involvement in clinical research. Journal of Family Nursing, 7, 7-31.

Instone, S.L. (2002). Developmental strategies for interviewing children. Journal of Pediatric Health Care, 16, 304-305.

Knafl, K., Breitmayer, B., Gallo, A., \& Zoeller, L. (1996). Family response to childhood chronic illness: Description of management styles. Journal of Pediatric Nursing, 11, 315-326.

Knafl, K.A., \& Deatrick, J.A. (2002). The challenge of normalization for families of children with chronic conditions. Pediatric Nursing, 28, 49-53.

Kortesluoma, R.-L., Hentinen, M., \& Nikkonen, M. (2003). Conducting a qualitative child interview: Methodological considerations. Journal of Advanced Nursing, 42, 434-441.

Miles, M.B., \& Huberman, A.M. (1994). Qualitative data analysis: An expanded sourcebook. Thousand Oaks, CA: Sage.

Morison, M., Moir, J., \& Kwansa, T. (2000). Interviewing children for the purposes of research in primary care. Primary Health Care Research \& Development, 1, 113-130.

National Commission for the Protection of Human Subjects of Biomedical and Behavioral Research. (1978). The Belmont Report: Ethical principles and guidelines for the protection of human subjects of research. Washington, DC: U.S. Government Printing Office.

National Institutes of Health. (1998). NIH policy and guidelines on the inclusion of children as participants in research involving human subjects. Retrieved June 20, 2007, from http:/grants.nih.gov/grants/ guide/notice-files/not98-024.html

Patton, M. (2002). Qualitative research and evaluation methods (3rd ed.). Thousand Oaks, CA: Sage.

Pediatric Research Equity Act. (2003; enacted). 108th Cong., 149 Cong. Rec. Retrieved April 2, 2007, from http://www.fda.gov/cder/pediatric/S-650-PREA.pdf

Pletsch, P.K., \& Stevens, P.E. (2001). Children in research: Informed consent and critical factors affecting mothers. Journal of Family Nursing, 7, $50-70$. 
Robinson, C.A. (1993). Managing life with a chronic condition: The story of normalization. Qualitative Health Research, 3, 6-28.

Rodriguez, A., Tuvemo, T., \& Hansson, M.G. (2006). Parents' perspectives on research involving children. Upsala Journal of Medical Sciences, 111, 73-86.

Sandelowski, M. (2000). Whatever happened to qualitative description? Research in Nursing \& Health, 23, 334-340.

Santelli, J.S., Rogers, A.S., Rosenfeld, W.D., DuRant, R.H., Dubler, N., Morreale, M., et al. (2003). Guidelines for adolescent health research: A position paper of the Society for Adolescent Medicine. Journal of Adolescent Health, 33, 396-409.

Smyth, R.L. (2001). Research with children: Paediatric practice needs better evidence-gained in collabo- ration with parents and children. British Medical Journal, 322, 1377-1378.

Snethen, J.A., Broome, M.E., Knafl, K., Deatrick, J.A., \& Angst, D.B. (2006). Family patterns of decisionmaking in pediatric clinical trials. Research in Nursing \& Health, 29, 223-232.

Ungar, D., Joffe, S., \& Kodish, E. (2006). Children are not small adults: Documentation of assent for research involving children. Journal of Pediatrics, 149, S31-S33.

U.S. Congress, Office of Technology Assessment. (1991). Adolescent health-Volume I: Summary and policy options. OTA-H-468. Washington DC: US Government Printing Office. Retrieved June 20, 2007 from http://www.wws.princeton.edu/ota/disk1/1991/ 9102/9102.PDF 